\title{
Near-Infrared Fluorescence Lymphatic Imaging to Reconsider Occlusion Pressure of Superficial Lymphatic Collectors in Upper Extremities of Healthy Volunteers
}

\author{
Jean-Paul Belgrado, PT, MSc, ${ }^{1-3}$ Liesbeth Vandermeeren, MD,, ${ }^{1,2,4}$ Sophie Vankerckhove, MsSc, ${ }^{1,2}$ \\ Jean-Baptiste Valsamis, IngPhD, ${ }^{1-3}$ Julie Malloizel-Delaunay, MD, \\ Jean-Jacques Moraine, PT, PhD, ${ }^{1,6}$ and Fabienne Liebens, MD ${ }^{2,7}$
}

\begin{abstract}
Background: There are very little scientific data on occlusion pressure for superficial lymphatic collectors. Given its importance in determining the transport capacity of lymphatic vessels, it is crucial to know its value. The novel method of near-infrared fluorescence lymphatic imaging (NIRFLI) can be used to visualize lymphatic flow in real time. The goal of this study was to see if this method could be used to measure the lymphatic occlusion pressure.

Methods: We observed and recorded lymph flow in the upper limb of healthy volunteers through a transparent cuff using near-infrared fluorescence lymphatic imaging. After obtaining a baseline of the lymph flow without pressure inside the cuff, the cuff was inflated by increments of $10 \mathrm{~mm} \mathrm{Hg}$ starting at $30 \mathrm{~mm} \mathrm{Hg}$. A NIRFLI guided manual lymphatic drainage technique named "Fill \& Flush Drainage Method" was performed during the measurement to promote lymph flow. Lymphatic occlusion pressure was determined by observing when lymph flow stopped under the cuff.

Results: We measured the lymphatic occlusion pressure on 30 healthy volunteers (11 men and 19 women). Mean lymphatic occlusion pressure in the upper limb was $86 \mathrm{~mm} \mathrm{Hg}(\mathrm{CI} \pm 3.7 \mathrm{~mm} \mathrm{Hg}, \alpha=0.5 \%)$. No significant differences were found between age groups $(p=0.18)$, gender $(p=0.12)$, or limb side $(p=0.85)$.

Conclusions: NIRFLI, a transparent sphygmomanometer cuff and the "Fill and Flush" manual lymphatic drainage method were used to measure the lymphatic occlusion pressure in 30 healthy humans. That combination of these techniques allows the visualization of the lymph flow in real time, while ensuring the continuous filling of the lymph collectors during the measurement session, reducing false negative observations. The measured occlusion pressures are much higher than previously described in the medical literature.
\end{abstract}

\section{Introduction}

$\mathbf{T}$ HE LYMPHATIC SYSTEM IS A KEYSTONE of fluid homeostasis in the interstitium, given that filtered fluids return to the circulation mostly through the lymphatics. ${ }^{1}$ Insufficient lymphatic transport causes lymph stasis, leading to progressive swelling of the insufficiently drained anatomical area. Lymph transport is produced by mechanical forces, generated by contraction of the smooth muscle cells ${ }^{2}$ that are located in the collecting lymphatic wall. This contraction induces intraluminal pressure to create lymphatic pumping.

Increased understanding of lymphatic pump force values in humans could provide valuable data to aid in the treatment of lymphedema ${ }^{3}$ in the evaluation of potential therapeutic products and devices research.

\footnotetext{
${ }^{1}$ Lymphology Research Unit, ${ }^{2}$ Clinique de Lymphologie, ${ }^{3}$ BEAMS (Bio, Electro, and Mechanical Systems), ${ }^{4}$ Plastic and Reconstructive Surgery Department, and ${ }^{6}$ Research Unit in Cardiorespiratory Physiology, Université libre de Bruxelles, Bruxelles, Belgium.

${ }^{5}$ Vascular Medicine Department and ${ }^{7}$ Breast Clinic, CHU St. Pierre, Bruxelles, Belgium.

(C) Belgrado et al, 2016; Published by Mary Ann Liebert, Inc. This Open Access article is distributed under the terms of the Creative Commons Attribution Noncommercial License (http://creativecommons.org/licenses/by-nc/4.0/) which permits any noncommercial use, distribution, and reproduction in any medium, provided the original author(s) and the source are credited.
} 
However, direct measurement of intraluminal lymphatic pressure requires surgical cut-down ${ }^{4}$ and is not ethically acceptable. ${ }^{3}$ The easiest approach to evaluate superficial lymphatic pump forces is very similar to what is widely used for arterial blood pressure: the sphygmomanometer.

\section{Lymphatic vessel physiology}

Superficial lymphatic collectors consist of very thinwalled, collapsible, porous, ${ }^{5,6}$ and translucent tubes. Superficial collectors are numerous and run parallel to the skin surface. They drain the pre-collectors coming from the initial lymphatics and are organized like links in a chain (Fig. 1A). Each link is called a lymphangion, the diameter of which at rest ranges between 0.08 to $0.8 \mathrm{~mm}^{7,8}$ Endothelium folds ${ }^{6}$ provide a bicuspid check valve at each end of the lymphangion, preventing fluid backflow. The lymphangion are lined by smooth muscle cells, ${ }^{8}$ which when they contract contribute actively to lymph transport by propeling the lymph bolus downstream. ${ }^{9}$

Contractions are not rhythmic all along the collectors ${ }^{10}$ and often short sections composed of 2 to 5 contiguous lymphangions contract vigorously in an ordered sequence to propel the lymph in a centripetal direction. The contraction only starts when a lymphangion contains enough lymph to stretch its endothelium. Relationships between lymphatic transmural pressures and nitrous oxide contribute to the adjustment of lymphatic pumping. ${ }^{9}$ Recently, Cajal-like cells ${ }^{11}$ were identified inside the wall of the main collector, the thoracic duct.
They are probably involved in the neuromuscular organization of lymph propulsion. The complex neuro-mechanic transduction response, which provokes and coordinates the lymph bolus propulsion, needs more investigation to be clearly understood.

Lymphatic flow is not continuous. If a segment of a lymph collector does not contain enough lymph to trigger the contraction, it remains inactive, sometimes for several minutes. Lymph formation is promoted by pressure gradient oscillations and shearing forces between interstitium and initial lymphatics. Arterial pulsatility, hydrostatic pressure, periodic deformation of environmental tissue, as in walking or massage, impact lymph formation. ${ }^{6,12}$

\section{Direct measurement of intra-lymphatic pressure}

In 1979, Olszewski and Engeset ${ }^{13}$ performed a direct measurement of intra-lymphatic pressure by cannulating the superficial lymphatic collectors in the lower extremities of 12 healthy men. They concluded that the systolic lymph end pressure generated by the intrinsic contractions of the lymphatics ranges from 1 to $40 \mathrm{~mm} \mathrm{Hg}$. However, two of their subjects reached recorded values of $120 \mathrm{~mm} \mathrm{Hg}$. In further publications, they confirmed the large range of pressure observed with their method.

\section{Occlusion pressure}

Using less invasive method in conjunction with imaging, others authors have indirectly measured the pressure at which
A

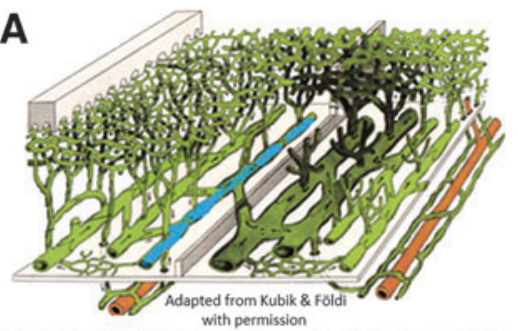

Normaly, initial lymphatic network is not visible on lymphofluoroscopy, it drains into functional lymphatic collectors which are clearly visible. Rosary image (triple arrow) is typical of lymphangions separated by their valves. Bolus of lymph are visible (double arrow) covering the distance of 2 to 4 lymphangions

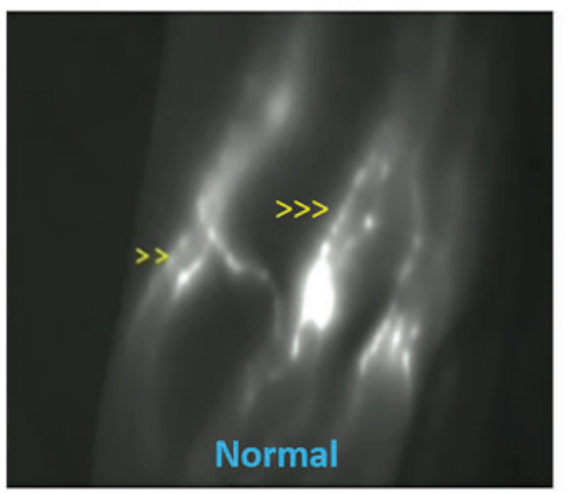

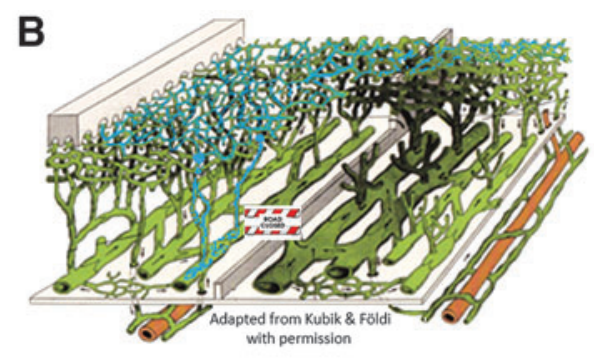

Impairment of lymphatic collectors reroute the lymph towards the initial lymphatics enlarging the vessels and making them visible as tortuous vessels. These vessels are not provide with valves. Dense white points (small arrow) are visible precollectors.

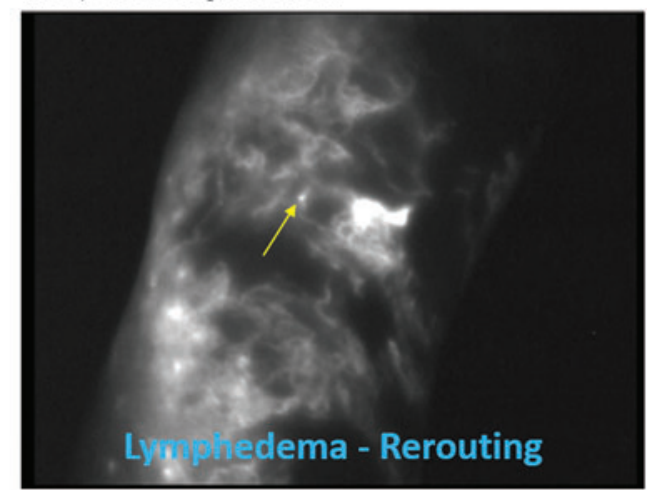

FIG. 1. NIRFLI of the superficial lymphatic network and its schematic architecture. (A) In a normal condition, the lymph flows through the superficial collectors. (B) In a lymphedematous situation, the lymph is rerouted through the initial lymphatic network. Note: The schematic architecture of the superficial lymphatic network is adapted from Földi et al. ${ }^{36}$ with written permission. 
lymphatic flow was occluded. Miller and Seale ${ }^{14}$ injected ${ }^{99 \mathrm{~m}}$ Tc colloids subcutaneously into the hind thighs of $16 \mathrm{dogs}$ and, using a gamma ray detector, determined that the lymphatic occlusion pressure was $75 \mathrm{~mm} \mathrm{Hg}$. However, they rejected the measurement of one animal where lymph flow was still observed at $75 \mathrm{~mm} \mathrm{Hg}$.

In another study, Modi et al. ${ }^{3}$ determined the occlusion pressure of the superficial lymphatics in 16 normal human subjects to be $39 \pm 14 \mathrm{~mm} \mathrm{Hg}$ by observing the clearance of a radiolabeled colloid $\left(99^{\mathrm{m}} \mathrm{Tc}-\mathrm{HIG}\right)$. More recently, Rasmussen et al. ${ }^{15}$ used NIRFLI to image real time lymphatic pumping in humans, and Tan et al. ${ }^{16}$ observed the lymphatic response to manual lymphatic drainage. Using this technique to image the lymphatic flow in 30 normal legs, Unno et al. ${ }^{17}$ measured the occlusion pressure of the lymphatic collectors to be $23.9 \pm 16 \mathrm{~mm} \mathrm{Hg}$.

\section{Superficial lymph collector's occlusion pressure and lymphedema treatment}

The physical treatment of lymphedema intends to move the fluid out of the stasis area by applying forces on the edema. Pressure variations are frequently provided by manual lymph drainage, compression therapy devices, and/ or multicomponent bandages and sleeves. Knowing the occlusion pressure of individual subjects would improve the balancing act between applying sufficient pressure to reduce the edema but not enough to occlude vessels. Eliska and Eliskova ${ }^{18}$ concluded in a study of the lymphatic collectors in human feet and dog hind paws, that massages applying external pressures of $70-100 \mathrm{~mm} \mathrm{Hg}$ affected the endothelial lining of the initial lymphatic vessels, resulting in damage to collecting lymphatic vessels. Casley-Smith et al. ${ }^{19}$ fears that deep heavy-handed massage may damage tissues.

Although the occlusion pressure of the lymphatic collectors is never mentioned in the consensus documents of the International Society of Lymphology ${ }^{20}$ nor in the International Lymphedema Framework, ${ }^{21}$ the content of both of these reference documents regards pressure as a core factor in lymphedema treatment, with every paragraph dealing with manual lymph drainage, multicomponent bandages, or intermittent compression therapy evoking pressure "values" repeatedly. They clearly display the need to apply enough pressure to be efficient but are unclear what the threshold to avoid occlusion of the lymphatic system should be, using terms such as "excessive pressure," "desired pressure," "gentle pressure," "optimal pressure" to describe the levels of pressure.

Despite the precautionary principle contained in the consensus documents, the authors ${ }^{22}$ recommend the application of pressures of 30,50 , and $90 \mathrm{~mm} \mathrm{Hg}^{23}$ or even higher than $120 \mathrm{~mm} \mathrm{Hg}^{24}$ when using mechanical compression devices. However, the only currently used compression devices that use precise pressure values are compression sleeves.

In operative lymphedema treatments, ${ }^{25}$ the published success of the lympho-venous anastomoses assumes a difference in pressure between lymphatic and venous flow, in other words it is assumed that higher pressures in the lymph collectors allow the lymphatic flow to run into the vein without reflux.
In order to try to resolve the discrepancies between scientific publications, consensus documents, concepts, and clinical opinions, we designed the current study to measure the occlusion pressure of superficial lymphatic collectors in healthy volunteers. As described below, we used NIRFLI, a transparent sphygmomanometer cuff, and the "Fill and Flush" manual lymph drainage method to measure the occlusion pressure.

\section{Materials and Methods}

\section{Study design}

The study was conducted at the Academic Hospital of the "Université Libre de Bruxelles", at the Lymphology Research Unit, including an interventional protocol.

\section{Approvals}

The study was approved by the local ethical committee of the Academic Medical Center Saint Pierre, Université libre de Bruxelles reference: AK/14/07-62/4391 and by the Belgian federal agency of drugs, registered under the EudraCT number: 2014-002501-38 and the NCT 02359578.

\section{Study participants}

Healthy adult volunteers, male and female, were recruited by advertising at the university. The experiments were performed between August 2014 and January 2015. We categorized the subjects into three age groups (21-34, 35-49, 50+ years). All eligible subjects provided written informed consent.

\section{Quality of images}

The injection sites were covered with non-porous black tape to avoid oversaturation of the camera, spreading of ICG on the skin, and an undesirable fluorescent background in the images. Fluorescence imaging of the lymphatic flow was observed by fixing the camera (Photo Dynamic Eye, Hamamatsu $\left.{ }^{\circledR}\right) 15 \mathrm{~cm}$ above the investigation field (see supplementary video; supplementary material is available online at www.liebertpub.com/lrb).

\section{Exclusion criteria}

The exclusion criteria included coronary disease, pregnancy, allergy to iodine, breastfeeding women, advanced renal impairment, thyroid pathology, allergy to shellfish, primary and secondary lymphedema, oncological history, family history of lymphedema, and medication affecting smooth muscles, such as calcium channel antagonists.

\section{Limb under study}

Only one limb was studied in each subject because it has been shown that lateralization or handedness coincides with functional and/or anatomical asymmetries. ${ }^{26}$ In order to avoid any bias, the injected arm was randomized by tossing a coin.

\section{Position of the subject}

Subjects were seated on a chair; the arm was placed on a table at the heart level. 
The fluorescent dye used in the study was Indocyanine Green (Pulsion ${ }^{\circledR}$ ). $100 \mu \mathrm{g}$ diluted in a volume of $0.5 \mathrm{~mL}$ pure water were injected intradermally into the first interdigital space. Indocyanine Green (ICG) is currently used to assess lymphatic contractility. ${ }^{17,27-30}$ Its concentration does not influence lymphatic function. ${ }^{31}$ Only rare cases of allergy, ${ }^{32}$ when intravenously injected at high dosages have been reported, but no other evidence of adverse effects such as neurotoxicity ${ }^{33}$ are reported. Until the present, we have performed more than thousand NIRFLI in patients and normal subjects and have never observed any adverse effects. Only a small green point remained at the injection point that disappears after a few days.

\section{Position of the camera}

The optical axis of the fixed camera was perpendicular to the volar region of the arm and perpendicular to the long axis of the observed collector. Images were recorded on a hard disk throughout the experiment.

\section{Filling of the lymph collectors}

To ensure that superficial lymphatic collectors were filled with lymph and therefore pumping, during the whole experiment we manually filled the collectors that were distal of the cuff, performing an optimized manual lymphatic drainage. We called this technique the "Fill and Flush Drainage Method" (FFDM), a NIRFLI guided manual lymphatic drainage developed in our laboratory. The efficiency of the FFDM applied on the entire forearm of a normal subject is shown in the video.

The method includes two maneuvers:

1. The "Fill" maneuver aims to force fluid and ICG from the interstitium into the initial lymphatic network. This maneuver is a short rolling and stretching movement, achieved by applying perpendicular and tangential forces on the skin in order to produce the correct pressure. It is performed with the thumb and not with the whole hand. It is repeated four consecutive times, pushing the fluid proximally from the injection point.

2. After the "Fill" maneuver, the second maneuver, called the "Flush" maneuver, aims to flush the lymph through the collectors. Two consecutive "Flush" maneuvers are sufficient to empty the collectors. They are executed with the lateral side of the thumb and the medial side of the index finger, with both fingers forming an open ring and applying perpendicular and tangential forces moving the hand from the "Fill" point to proximal.

During the measurement session, we focused the FFDM on a restricted area that drained only one or two collectors that are vertical to the optical axis of the fixed camera. In order to not force the lymph flow under the cuff by the flushing maneuver, we flush the lymph from the injection point to proximal and stop the maneuver at the line drawn $5 \mathrm{~cm}$ distally to the distal side of the transparent cuff.

FFDM as described was performed throughout the whole measurement session to ensure a fill in of the lymph. One measurement session takes around 15 minutes.

\section{The sphygmomanometer}

The sphygmomanometer was composed of a PVC transparent cuff connected to a precision digital manometer, $\mathrm{d}=0.1 \mathrm{~mm} \mathrm{Hg}$ (Testo ${ }^{\circledR} 510$ ). The pressure was displayed in $\mathrm{mm} \mathrm{Hg}$ and induced using a manual manometric pump. A second pressure sensor (KIKUHIME TT MediTrade) was placed under the cuff for a supplementary pressure control. The cuff was placed on the arm above the elbow in the same place used to take blood pressure.

\section{Reference lines}

Five lines were drawn on the skin, with an infra-red fluorescent marker, perpendicular to the long axis of the limb. The first line was located $50 \mathrm{~mm}$ distal from the cuff and was used as stop point for the "Flush" maneuver. The second two lines were $50 \mathrm{~mm}$ apart and located under the cuff. The additional two lines were located above the cuff, $50 \mathrm{~mm}$ apart.

\section{Controlled variable}

The controlled variable in this study was the pressure into the compression cuff.

\section{Intervention}

Recording of the fluorescent images was started just before the injection and stopped at the very end of the experiment.

The baseline lymphatic flow was observed after a 3 minutes resting period, followed by a manual lymph drainage period of 2 minutes with the deflated cuff. We then inflated the cuff to an initial pressure of $30 \mathrm{~mm} \mathrm{Hg}$. After each successful lymph passage, we increased the cuff pressure by $10 \mathrm{~mm} \mathrm{Hg}$ (see video). The lymphatic occlusion pressure of the subject was defined as the pressure at which no lymph bolus flowed through the cuff within 5 minutes after the pressure increase. To confirm that the lymph system was still functioning properly, pressure was reduced by $10 \mathrm{~mm} \mathrm{Hg}$ and the return of lymph flow was observed.

\section{Data analysis}

Video sequences were randomized and blindly analyzed by two independent operators. They determined whether a lymph bolus was passing between the two reference lines situated under the cuff.

\section{Outcome measures}

The primary outcome was the cuff pressure which occluded the lymph flow. The secondary outcome compared the occlusion pressure between gender, handedness, and age.

\section{Statistical analysis}

The study was conducted on a total of 32 subjects, 2 subjects were excluded from the analysis because of instable pressure due to an imperfection in our first cuff.

Statistical analysis was made with MATLAB software, version 2008. The $p$-value indicated results from a two-sided Wilcoxon rank sum test (Mann-Whitney U test) in the case of two categories and a two-sided Kruskal-Wallis when the variable involves three categories. The power of the statistics 
TABle 1. Disaggregated Data: Individual VALUes of Superficial LyMPhatic OCCLUSION PRESSURE

\begin{tabular}{|c|c|c|c|c|}
\hline $\begin{array}{l}\text { Subject } \\
\text { [number] }\end{array}$ & $\begin{array}{c}\text { Side } \\
\text { [right/left] }\end{array}$ & $\begin{array}{c}\text { Age } \\
\text { [year] }\end{array}$ & $\begin{array}{c}\text { Gender } \\
\text { [female/male] }\end{array}$ & $\begin{array}{c}\text { Occlusion } \\
\text { pressure } \\
\text { [mmHg] }\end{array}$ \\
\hline 1 & $\mathrm{R}$ & 36 & $\mathrm{~F}$ & 80 \\
\hline 2 & $\mathrm{~L}$ & 26 & M & 80 \\
\hline 3 & $\mathrm{~L}$ & 24 & M & 80 \\
\hline 4 & $\mathrm{R}$ & 50 & $\mathrm{~F}$ & 80 \\
\hline 5 & $\mathrm{R}$ & 50 & M & 90 \\
\hline 6 & $\mathrm{R}$ & 25 & $\mathrm{~F}$ & 80 \\
\hline 7 & $\mathrm{~L}$ & 26 & $\mathrm{M}$ & 90 \\
\hline 8 & $\mathrm{~L}$ & 23 & M & 90 \\
\hline 9 & $\mathrm{R}$ & 26 & $\mathrm{~F}$ & 80 \\
\hline 10 & $\mathrm{R}$ & 24 & $\mathrm{~F}$ & 80 \\
\hline 11 & $\mathrm{R}$ & 32 & $\mathrm{~F}$ & 80 \\
\hline 12 & $\mathrm{R}$ & 31 & $\mathrm{~F}$ & 90 \\
\hline 13 & $\mathrm{~L}$ & 43 & M & 90 \\
\hline 14 & $\mathrm{R}$ & 52 & $\mathrm{~F}$ & 90 \\
\hline 15 & $\mathrm{~L}$ & 39 & $\mathrm{~F}$ & 80 \\
\hline 16 & $\mathrm{R}$ & 38 & M & 90 \\
\hline 17 & $\mathrm{R}$ & 45 & $\mathrm{~F}$ & 80 \\
\hline 18 & $\mathrm{~L}$ & 51 & $\mathrm{~F}$ & 80 \\
\hline 19 & $\mathrm{~L}$ & 62 & $\mathrm{~F}$ & 90 \\
\hline 20 & $\mathrm{R}$ & 51 & $\mathrm{~F}$ & 100 \\
\hline 21 & $\mathrm{R}$ & 53 & $\mathrm{~F}$ & 100 \\
\hline 22 & $\mathrm{~L}$ & 57 & M & 90 \\
\hline 23 & $\mathrm{~L}$ & 40 & M & 80 \\
\hline 24 & $\bar{L}$ & 78 & $\mathrm{~F}$ & 80 \\
\hline 25 & $\mathrm{R}$ & 40 & $\mathrm{~F}$ & 90 \\
\hline 26 & $\mathrm{R}$ & 50 & $\mathrm{~F}$ & 90 \\
\hline 27 & $\mathrm{~L}$ & 52 & M & 100 \\
\hline 28 & $\mathrm{~L}$ & 50 & M & 90 \\
\hline 29 & $\mathrm{R}$ & 50 & $\mathrm{~F}$ & 80 \\
\hline 30 & $\mathrm{R}$ & 59 & $\mathrm{~F}$ & 80 \\
\hline
\end{tabular}

has been computed for a sample of size 30 with the statistics centered on the lower boundary of the confidence interval (CI) of $82.3 \mathrm{~mm} \mathrm{Hg}$, giving a value of $1-\beta=82.7 \%$. With a statistics of $60 \mathrm{~mm} \mathrm{Hg}$, which is the maximum value reported in the literature, the value $1-\beta \approx 100 \%$.

\section{Results}

The data from 30 healthy volunteers who participated in the study were analyzed. The mean age of the analyzed participants was $43 \pm 14$ years. There were 19 women and 11 men.

Disaggregated data are given in Table 1, aggregated data and descriptive statistics in Table 2. Table 3 shows the repartition of the sample among gender, limb side, and age.
Table 3. Data Repartition Among Gender, SIDE, AND AGE*

\begin{tabular}{lcccc}
\hline Type & Value & Size & Percentage & p-value \\
\hline Gender & Female & 19 & 63.3 & 0.12 \\
& Male & 11 & 36.7 & \\
Side & Left & 13 & 43.3 & 0.853 \\
& Right & 17 & 56.7 & \\
Age & $21-34$ & 9 & 30.0 & 0.188 \\
& $35-49$ & 7 & 23.3 & \\
& $>50$ & 14 & 46.7 & \\
\hline
\end{tabular}

*The $p$-values result from Wilcoxon rank sum test (gender and side) and Kruskal-Wallis (age). No significant differences have been observed.

Due to the reduced size of the sample, we considered a value of $\alpha=0.5 \%$.

In fifteen subjects, the measured occlusion pressures were $80 \mathrm{~mm} \mathrm{Hg}$, in 12 subjects, $90 \mathrm{~mm} \mathrm{Hg}$, and for $3,100 \mathrm{~mm} \mathrm{Hg}$. In all subjects the lymph flow was restored after reducing the pressure by $10 \mathrm{~mm} \mathrm{Hg}$, confirming that the lymph system was still functioning properly.

Mean lymphatic occlusion pressure on the upper limb was $86 \mathrm{~mm} \mathrm{Hg}(\mathrm{CI} \pm 3.7 \mathrm{~mm} \mathrm{Hg}, \alpha=0.5 \%$ ) (Table 2). There was no discrepancy between the results of the two operators who assessed the images.

Using "Fill and Flush" manual lymph drainage method, a lymph bolus passage appeared approximately every $30 \mathrm{sec}$ under baseline conditions. As the pressure increased, the delay between the passage of boluses of lymph also increased. The time between the two last passages, just before the occlusion, was around 1 minute.

No significant difference was found between age group ( $p=0.18)$, gender $(p=0.12)$, or limb side $(p=0.85)$ (Table 3$)$.

At the end of the experiment, the redness due to the compression disappeared after a few minutes. At the end of the experiment, the distal lymphatic collectors seemed widened, but as we reduced the infra-red light intensity the vessel walls reappeared as initially. A fluorescent cloud image appears along the extravascular wall indicating that a part of the free ICG passed through the vessel's wall.

We did not identify any late onset adverse effects at the follow-up examination 1 month after the experiment.

\section{Discussion}

Thirty five years ago, the first study exploring the maximum operating pressure inside lymphatics was published. ${ }^{13}$ This pioneering study involved 12 healthy volunteers and was invasive, painful, and complex to interpret. Since then,

Table 2. Aggregated Data: Descriptive Statistics

\begin{tabular}{lccccccc}
\hline & $\begin{array}{c}\text { Subjects } \\
\text { [number] }\end{array}$ & $\begin{array}{c}\text { Left side } \\
\text { [number] }\end{array}$ & $\begin{array}{c}\text { Right side } \\
\text { [number] }\end{array}$ & $\begin{array}{c}\text { Age } \\
\text { [yr] }\end{array}$ & $\begin{array}{c}\text { Female } \\
\text { [number] }\end{array}$ & $\begin{array}{c}\text { Male } \\
\text { [number] }\end{array}$ & $\begin{array}{c}\text { Occlusion pressure } \\
\text { [mmHg] }\end{array}$ \\
\hline $\mathrm{n}$ & 30 & 13 & 17 & & 19 & 11 & \\
Mean & & & & 43 & & & 86.00 \\
$\mathrm{SD}$ & & & & 14 & & & 6.75 \\
\hline
\end{tabular}


the fundamental knowledge about the range of intra-lymphatic pressure and associated lymphatic occlusion pressure has not been clearly shown. This is primarily due to a lack of a simple and controlled noninvasive technique. This missing knowledge about the underlying physiology has left the field open for several contradictory physiological and therapeutic concepts. $^{20,21,24}$

Compared to the results reported by other authors, ${ }^{3,14,17}$ our data indicate significantly higher occlusion pressure values, reaching one of the highest values measured in the original study. ${ }^{34}$

Result discrepancies with other studies may be explained by study design and methodology. For example, Unno et al. ${ }^{17}$ started at $60 \mathrm{~mm} \mathrm{Hg}$ and decreased the cuff compression progressively. They assumed, based on literature, that the occlusion pressure would be under this threshold, even though, at $60 \mathrm{~mm} \mathrm{Hg}$, they did not reach the occlusion pressure. At that value, the cuff induces a sufficient resistance to slow down the lymph flow, causing first a distal augmented pressure in the lymph collectors, then an increase of the wall pressure, and finally an increase of the physiologic leakage ${ }^{5,8}$ of water and other small molecules such as free ICG.

As we observed and then hypothesized, due to the lymphangionic porosity, $8,35,36$ and the distal pressure of the cuff, one part of the water and small molecules such as free ICG, cross the lymphatic collector's wall, provoking a distal leakage. The fluid that left the observed lymphatic vessels returns to the interstitium instead of being pumped forwards. Consequently, fewer lymph boluses reach the region of interest in a given period of time. If the observation time is not long enough, 5 minutes in Unno's et al. study, ${ }^{17}$ this phenomenon can be misinterpreted: a "pseudostop" of lymph flow can be interpreted as lower than the real occlusion pressure.

Moreover, Unno et al. ${ }^{17}$ injected the ICG subcutaneously, ${ }^{17}$ instead of intradermally as in studies by us and Modi et al. ${ }^{3}$ The best way to observe the superficial lymphatic system using a dye or a radiotracer, is obtained following intradermal injection. ${ }^{37}$ Subcutaneous injection changes totally the results, ${ }^{38}$ as the dye needs more time to reach the lymphatic system.

Also, in our study, we ensured the fill of the lymphatics, knowing that lymphatic flow is an interrupted fluid column, ${ }^{9}$ dependent on the filtration rate and distal fluid balance. The frequency of lymph bolus passage in collectors at a given moment depends on many parameters: filtration rate, local tissue shear forces, and position of the subject during the experiment. For example, a supine position at rest reduces microcirculation pressure, then filtration, and consequently lymph formation. ${ }^{1,8,39}$.

In supine or seated positions at rest, the waiting time for a lymph bolus passage can be long. If the observation time between two bolus passages is not sufficient, the absence of bolus passage during this period could be interpreted as a lymph flow stop. To avoid this false negative observation and to ensure the continuous presence of lymph in the observed collectors, we filled up the lymph collector by FFDM, our optimized manual lymph drainage. The other referenced study's methodology waits passively for lymph bolus passages. Using FFDM, a lymph bolus crosses the cuff approximately every 30 seconds.

Modi et al.'s study also included a group of lymphedematous patients; we have deliberately focused our study on healthy subjects. On the one hand, patients with an history of oncological surgery are at risk of developing secondary lymphedema (guidelines and literature mention that a latent lymphedema may be triggered by a blood pressure cuff procedure on the limb at risk $^{40}$ ); on the other hand, the impairment of the superficial lymphatic collectors makes them poorly visible, not visible or absent.

In lymphedema, most fluid leaves the interstitium through the dilated initial lymphatic network (Fig. 1B). These tiny vessels without valves or muscles convey the lymph by capillarity and pressure gradient. We believe that in the lymphedematous limb, results obtained by any occlusion method have to be interpreted more as the reflection of the superficial initial lymphatics occlusion than as the occlusion of the collecting and ultimately the collectors' pumping force.

The pressure exerted by the hand on the skin during massage does not exceed $10 \mathrm{~mm} \mathrm{Hg},{ }^{41}$ ensuring that therapists do not occlude superficial lymph collectors. Intermittent compression therapy devices exert more pressure. ${ }^{41}$ Preloaded collectors can be flushed during chamber inflation, but if the pressure reaches the occlusion pressure, initial lymphatics and collectors could be occluded during the inflation period phase.

We have demonstrated that our method can be used to assess the occlusion lymphatic pressure in a clinical setting in healthy subjects. There is a potential use in pharmaceutical research investigating drugs, devices, and techniques for improving lymph transport in vivo. The advantage of this method is that lymphangion contraction and the fluid transportation are visible in real time.

\section{Conclusions}

Near-infrared fluorescence lymphatic imaging observed through a transparent cuff can be used to study and measure the superficial lymphatic occlusion pressure. The measured occlusion pressures are significantly higher than those that have been previously published in the medical literature, because we performed an optimized manual lymph drainage (FFDM) during the whole experiment, ensuring the continuous filling of the lymph collectors. In these conditions, lymph bolus passage rate is increased, avoiding false negative observations due to a short waiting time between two bolus passages or less lymph production conditions.

In our experiment, the observed mean occlusion pressure of the superficial lymphatic vessels was $86 \pm$ IC $3.7 \mathrm{~mm} \mathrm{Hg}$. No difference was found between gender, age groups, nor limb side. This new knowledge about lymphatic physiology may lead to an adaptation and optimization of the preexisting lymphedema physiopathology as in treatment concepts.

\section{Acknowledgments}

The authors thank the healthy volunteers that participated in this study.

To S. Degrande: data base encoding; To T. d'Angelo and E. Hortmans for technical assistance on imaging; To Eureduc ${ }^{\circledR}$ for provide transparent cuff; To J. Wigg, N. Röh, B. Chikly, and C. Lois Röh for English reviewing; To Pr. P. Mortimer and Pr. N. Piller for their critical advice. 


\section{Author Disclosure Statement}

The authors declare no financial conflict of interest. The study was self-funded.

\section{References}

1. Woodcock TE, Woodcock TM. Revised Starling equation and the glycocalyx model of transvascular fluid exchange: An improved paradigm for prescribing intravenous fluid therapy. Brit J Anaesth 2012;108:384-394.

2. von der Weid PY, Zawieja DC. Lymphatic smooth muscle: The motor unit of lymph drainage. Int $\mathrm{J}$ Biochem Cell Biol 2004;36:1147-1153.

3. Modi S, Stanton AW, Svensson WE, Peters AM, Mortimer PS, Levick JR. Human lymphatic pumping measured in healthy and lymphoedematous arms by lymphatic congestion lymphoscintigraphy. J Physiol 2007;583:271-285.

4. Olszewski WL, Engeset A. Intrinsic contractility of prenodal lymph vessels and lymph flow in human leg. Am J Physiol 1980;239:H775-783.

5. Scallan JP, Davis MJ, Huxley VH. Permeability and contractile responses of collecting lymphatic vessels elicited by atrial and brain natriuretic peptides. J Physiol 2013;591: 5071-5081.

6. Breslin JW. Mechanical forces and lymphatic transport. Microvasc Res 2014;96:46-54.

7. Tourani SS, Taylor GI, Ashton MW. Anatomy of the superficial lymphatics of the abdominal wall and the upper thigh and its implications in lymphatic microsurgery. JPRAS 2013;66:1390-1395.

8. Huxley VH, Scallan J. Lymphatic fluid: exchange mechanisms and regulation. J Physiol 2011;589:2935-2943.

9. Gasheva OY, Zawieja DC, Gashev AA. Contractioninitiated NO-dependent lymphatic relaxation: A selfregulatory mechanism in rat thoracic duct. J Physiol 2006; 575:821-832.

10. Gashev AA. Lymphatic vessels: Pressure- and flowdependent regulatory reactions. Ann NY Acad Sci 2008; 1131:100-109.

11. Briggs Boedtkjer D, Rumessen J, Baandrup U, et al. Identification of interstitial Cajal-like cells in the human thoracic duct. Cells Tissues Organs 2013;197:145-158.

12. Ikomi E, Zweifach BW, Schmid-Schonbein GW. Fluid pressures in the rabbit popliteal afferent lymphatics during passive tissue motion. Lymphology 1997;30:13-23.

13. Olszewski WL, Engeset A. Lymphatic contractions. New Engl J Med 1979;300:316.

14. Miller GE, Seale JL. The recovery of terminal lymph flow following occlusion. J Biomechan Engineer 1987;109:7.

15. Rasmussen JC, Tan IC, Marshall MV, Fife CE, SevickMuraca EM. Lymphatic imaging in humans with nearinfrared fluorescence. Curr Opin Biotechnol 2009;20: 74-82.

16. Tan IC, Maus EA, Rasmussen JC, et al. Assessment of lymphatic contractile function after manual lymphatic drainage using near-infrared fluorescence imaging. Arch Phys Med Rehabil 2011;92:756-64.e1.

17. Unno N, Nishiyama M, Suzuki M, et al. A novel method of measuring human lymphatic pumping using indocyanine green fluorescence lymphography. J Vasc Surg 2010;52: 946-952.

18. Eliska O, Eliskova M. Are peripheral lymphatics damaged by high pressure manual massage? Lymphology 1995;28: 21-30.
19. Casley-Smith JR, Boris M, Weindorf S, Lasinski B. Treatment for lymphedema of the arm-the Casley-Smith method: A noninvasive method produces continued reduction. Cancer 1998;83:2843-2860.

20. Lymphology ISo. The diagnosis and treatment of peripheral lymphedema. 2009 Concensus Document of the International Society of Lymphology. Lymphology 2009;42: 51-60.

21. ILF. Lymphoedema Framework. Best Practice for the Management of Lymphoedema. International Consensus. London: MEP Ltd, 2006.

22. Belgrado J, Bourgeois P, Röh N, Moraine J. Intermittent pneumatic compression in the treatment of lymphedema: Current state of knowledge. Eur J Lymphology Relat Prob 2007;17:4-10.

23. Theys S, Deltombe T, Jamart J, Schoevaerdts J, Buche M. 30 or $90 \mathrm{~mm} \mathrm{Hg}$ - manual or pneumatic_-drainage in primary limb lymphedema: A comparative plethysmographic study. Eur J Lymphol Relat Prob 2004;12.

24. Zaleska M, Olszewski WL, Jain P, et al. Pressures and timing of intermittent pneumatic compression devices for efficient tissue fluid and lymph flow in limbs with lymphedema. Lymphat Res Biol 2013;11:227-232.

25. Boccardo F, De Cian F, Campisi CC, et al. Surgical prevention and treatment of lymphedema after lymph node dissection in patients with cutaneous melanoma. Lymphology 2013;46:20-26.

26. Bourgeois P, Leduc O, Belgrado J, Leduc A. Effect of lateralization and handedness on the function of the lymphatic system of the upper limbs. Lymphology 2010;43:78-84.

27. Tan IC, Maus EA, Rasmussen JC, et al. Assessment of lymphatic contractile function after manual lymphatic drainage using near-infrared fluorescence imaging. Arch Phys Med Rehabil 2011;92:756-764.e1.

28. Proulx ST, Luciani P, Derzsi S, et al. Quantitative imaging of lymphatic function with liposomal indocyanine green. Cancer Res 2010;70:7053-7062.

29. Unno N, Inuzuka K, Suzuki M, et al. Preliminary experience with a novel fluorescence lymphography using indocyanine green in patients with secondary lymphedema. J Vasc Surg 2007;45:1016-1021.

30. Rasmussen JC, Tan I-C, Marshall MV, et al. Human lymphatic architecture and dynamic transport imaged using near-infrared fluorescence. Translational Oncol 2010; 3:362-372.

31. Aldrich MB, Davies-Venn C, Angermiller B, et al. Concentration of indocyanine green does not significantly influence lymphatic function as assessed by near-infrared imaging. Lymphat Res Biol 2012;10:20-24.

32. Benya R, Quintana J, Brundage B. Adverse reactions to indocyanine green: A case report and a review of the literature. Cathet Cardiovasc Diagn 1989;17:231-233.

33. Toczylowska B, Zieminska E, Goch G, Milej D, Gerega A, Liebert A. Neurotoxic effects of indocyanine green. Cerebellar granule cell culture viability study. Biomed Optics Express 2014;5:800-816.

34. Olszewski WL, Engeset A. Intrinsic contractility of leg lymphatics in man. Preliminary communication. Lymphology 1979;12:81-84.

35. Scallan J, Huxley VH, Korthuis RJ, eds. Capillary Fluid Exchange Regulation, Functions and Pathology. Columbia 2010.

36. Földi M, Földi E, Kubik S, eds. Textbook of Lymphology for Physicians and Lymphedema Therapists: Urban \& Fischer; 2003. 
37. O'Mahony S, Rose SL, Chilvers AJ, et al. Finding an optimal method for imaging lymphatic vessels of the upper limb. Eur J Nuclear Med Mol Imag 2004;31:555-563.

38. Bourgeois P, Leduc O, Belgrado JP, Leduc A. Scintigraphic investigations of the superficial lymphatic system: Quantitative differences between intradermal and subcutaneous injections. Nucl Med Commun 2009;30:270-274.

39. Levick JR, Michel CC. Microvascular fluid exchange and the revised Starling principle. Cardiovasc Res 2010;87: 198-210.

40. Cheng CT, Deitch JM, Haines IE, Porter DJ, Kilbreath SL. Do medical procedures in the arm increase the risk of lymphoedema after axillary surgery? A review. ANZ J Surg 2014;84:510-514.
41. Segers P, Belgrado JP, Leduc A, Leduc O, Verdonck P. Excessive pressure in multichambered cuffs used for sequential compression therapy. Phys Ther 2002;82:1000-1008.

Address correspondence to: Jean-Paul Belgrado, PhD Lymphology Research Unit Faculté des Sciences de la Motricité Université Libre de Bruxelles Campus Erasme CP 640

Bruxelles 1070 Belgium

E-mail: belgrado@ulb.ac.be 